\title{
A Practical Approach to Lighting Design Course in an Electrical Engineering Programme
}

\author{
M. M. Travassos Valdez ${ }^{1}$, C. I. Faustino Agreira ${ }^{1}$, C. Machado Ferreira ${ }^{1}$, F. P. Maciel Barbosa ${ }^{2}$ \\ ${ }^{1}$ DEE, Instituto Superior de Engenharia de Coimbra, Coimbra, Portugal \\ ${ }^{2}$ INESC Porto and DEEC, Faculdade de Engenharia da Universidade do Porto, Porto, Portugal
}

\begin{abstract}
Technology has allowed new insights and creativity into the learning and teaching process and also enables to try out in a much more flexible, dynamic way other learning experiences. This constitutes in itself a more engaging role for teachers as well as students helping them to explore and create new areas, opening up, at the same time, new perspectives into the process and maximizing the availability and use of the current tools which the same technology provides. The facilitation in the investigation work development of projects renders the learning and teaching activities really appealing, allowing at the same time levels of effectiveness in this extremely modern and global era. This study integrates technology in the learning process and evaluation of its various outcomes. This case study describes the experience of two teachers with their class along a semester using computer aided technology for instruction and assessment. The task involved the lighting design of monuments with the purpose of attracting the on lookers' attention, enhancing the beauty and attributes of the façade of monuments or buildings considered relevant or of public interest. An approach of reinforcement learning applied to the historical monuments light configurations will be described.
\end{abstract}

Index Terms-Lighting design, illumination, education, problem based learning, virtual learning environment.

\section{INTRODUCTION}

The power and flexibility provided by information and communication technologies (ICT) promotes creativity levels in professional and personal lives, beyond wildest expectations. ICTs are clearly having a strong impact in the academic expertise of students while pushing the institutions to look for newer and better tools/programs in order to motivate the students and the teachers as well [1]. It has to be taken into account that all processes using ICTs may vary along the different stages, undoubtedly increasing in quality and effectiveness from the early to the final stages when the project is finally presented and assessed.

The paper concentrates on the use of ICT to bring polytechnic practise to the same level of training and expertise in line with the social, technological conditions and interactivity among universities. The aim is to engage in a new work practise involving methods, cooperation, interaction and interplay between physical and virtual learning environment [2].

The project included three specific objectives. The first one was to involve and teach students to develop and value critical thinking when facing professional issues in everyday situations. Other important objective was to boost the teaching and learning of key professional notions resorting to problem based learning, thus allowing the students to have plentiful access to purposeful real life contexts. The third goal was to promote access and understanding of critical problems in the field by providing real life scenarios.

This paper is organised as follows. Section I presents an introduction to the problem. Section II is devoted to the learning and teaching strategy that was used in this study. Section III presents a selection of the old monuments of the city of Coimbra that were illuminated. Section IV shows the results obtained using the software package Dialux 4.3. Finally, in section V, some conclusions that provide a valuable contribution to the understanding of the application of problem based learning combined with computer aided technology in the lighting design course are pointed out.

\section{LEARNING AND TEACHING STRATEGY}

In the lighting design course, it was incorporated a new way of learning and teaching. The students play an important role in the scenario presented through a virtual environment very similar to the real world. The learning objectives of the simulation were pre-defined and available to students, who were required to create strategies to reach these objectives. The scenario that they received might raise a number of issues and problems. The challenge was to identify and address the issues and problems from their own perspective and see how they could deal with them creatively. This is considered just as important as to explore creatively other problems that they think might be related to the issues raised.

The students were grouped in teams of four in order to maximize the learning potential of this simulation while keeping the group dynamics, particularly the communication and interpersonal skills required. They were also required to take into consideration all the legal and industrial obligations used in real life contexts [3].

At the end of the semester, all the students participated in a face-to-face forum to discuss any relevant issues raised during the process. The forum was used for the debriefing of students, teachers and professionals interested in the light design field. The discussions included the benefits of this particular teaching and learning strategy for both parties involved, teachers and students.

It was possible to adapt on-going lecture contents and learning activities in response to the developing dialogue throughout the simulation. The assessment consisted of reviewing and reflecting on the conceptual knowledge and

The $3^{\text {rd }}$ International Conference on Mobile and Computer Aided Learning, IMCL2008, www.imcl-conference.org 
understanding of working as a light engineer, as well as the process skills in participating in team work and using simulation resources.

In this study it was used the Dialux 4.3 software package [5]. It provided the relevant and meaningful simulations and allowed the desired problem based learning approach of the lighting project. The simulation software allows enough flexibility to meet the needs of the learning and teaching objectives of the course. The simulations have been found to significantly improve knowledge transfer [4]. This type of discovery-based learning using simulations has been shown to increase understanding of abstract concepts and increase student motivation [6], [7].

In this project-simulation, the students participated as active agents in the process of knowledge acquisition by learning to command the different tools and the available resources. Thus, they were actively involved in playing their roles. An anonymous evaluation instrument was used at the end of the course, in order to obtain an objective feedback from the participating students [8].

The simulation provided a variety of opportunities for students to interact with each other. With the simulation students were able to "practice skills" and explore sensitive areas. The majority of students rated the effectiveness of the simulation as being either high or very high. These conclusions gave a very positive feedback for the use of virtual environment simulations to promote understanding about contents, skills and values relevant to the proposed project.

Having adopted a constructivist approach in the project, it was asked to the students to rate its usefulness in terms of:

the perception and awareness gained in relation to professional practice matters of interest.

the overall learning benefits of having taken part in the cooperative project.

The project required them to reflect critically and extend their knowledge and understanding of major issues. The project replaced the conventional face-to-face tutorials/seminars and promotes a frequent contact between the students and the teachers. This required students to examine their own and other peoples' professional behavior. Table I shows the answers from students, concerning the usefulness of the cooperative work strategies.

It's considered very positive the fact that students had no difficulty in accepting the classmates' opinions (item 3 ), in collaborating/working with the others (item 8), in helping the others (item 5), in being a friend (item 9) and in having expressed their opinions and ideas (item 2).

These strategies sum up the fundamental attitudes, towards cooperative work. Students recognize the benefits of these strategies, in spite of having some difficulty in working with some of their group mates. Cooperative work fosters team work. The enthusiasm and the capacity to work with others are skills that they will have to develop in school. The results showing the impact of learning with cooperative work are presented in Table II. In a general way, it can be concluded that the experience had a positive impact in the way students learned.

TABLE I.
USEFULNESS OF COOPERATIVE WORK STRATEGIES

\begin{tabular}{|l|c|c|c|}
\hline \multicolumn{1}{|c|}{ Cooperative work list of subjects } & $\begin{array}{l}\text { VERY } \\
\text { USEFUL }\end{array}$ & $\begin{array}{l}\text { OF } \\
\text { LITLLE } \\
\text { USE }\end{array}$ & $\begin{array}{l}\text { NOT } \\
\text { USEFUL }\end{array}$ \\
\hline 3 - I respected my classmates' opinions. & $\mathbf{1 9}$ & 4 & 0 \\
\hline 8 - I collaborated/worked with the others. & $\mathbf{1 9}$ & 4 & 0 \\
\hline 5 - I helped the others. & $\mathbf{1 9}$ & 4 & 0 \\
\hline 9 - I was a friend. & $\mathbf{1 9}$ & 4 & 0 \\
\hline 2 - I expressed my views and ideas. & $\mathbf{1 8}$ & 5 & 0 \\
\hline 4 - I asked the others for help. & $\mathbf{1 7}$ & 5 & 1 \\
\hline $\begin{array}{l}\text { 6 - I tried to help to solve the group's } \\
\text { problems. }\end{array}$ & $\mathbf{1 5}$ & 8 & 0 \\
\hline $\begin{array}{l}\text { 1 - I worked hard and with enthusiasm. } \\
\text { 7 - I encouraged the others to get } \\
\text { involved in the project. }\end{array}$ & $\mathbf{1 4}$ & 9 & 0 \\
\hline
\end{tabular}

TABLE II

IMPACT OF LEARNING WITH COOPERATIVE WORK

\begin{tabular}{|c|c|c|c|}
\hline Cooperative work list of subjects & $\begin{array}{l}\text { VERY } \\
\text { USEFUL }\end{array}$ & $\begin{array}{l}\text { OF } \\
\text { LITLLE } \\
\text { USE }\end{array}$ & $\begin{array}{l}\text { NOT } \\
\text { USEFUL }\end{array}$ \\
\hline 1 - I was motivated to learn & $\begin{array}{c}16 / \\
69.5 \%\end{array}$ & $\begin{array}{c}7 / \\
30.4 \%\end{array}$ & 0 \\
\hline $\begin{array}{l}2 \text { - I used several strategies to solve } \\
\text { difficulties }\end{array}$ & $\begin{array}{c}9 / \\
39.1 \%\end{array}$ & $\begin{array}{c}13 / \\
56.5 \%\end{array}$ & $\begin{array}{c}1 / \\
4.3 \% \\
\end{array}$ \\
\hline $\begin{array}{l}3 \text { - I focused my attention to select the } \\
\text { information I needed }\end{array}$ & $\begin{array}{c}13 / \\
56.5 \%\end{array}$ & $\begin{array}{c}10 / \\
43.3 \%\end{array}$ & 0 \\
\hline $\begin{array}{l}4 \text { - I developed strategies of cooperative } \\
\text { work }\end{array}$ & $\begin{array}{c}10 / \\
43.3 \%\end{array}$ & $\begin{array}{c}13 / \\
56.5 \%\end{array}$ & 0 \\
\hline $\begin{array}{l}5 \text { - I reflected about my learning } \\
\text { (objectives, strategies and my progress) }\end{array}$ & $\begin{array}{c}13 / \\
56.5 \%\end{array}$ & $\begin{array}{c}10 / \\
43.3 \% \\
\end{array}$ & 0 \\
\hline 6 - I asked the others for help & $\begin{array}{c}14 / \\
60.8 \%\end{array}$ & $\begin{array}{c}9 / \\
39.1 \% \\
\end{array}$ & 0 \\
\hline $\begin{array}{l}7 \text { - I tried to clarify my doubts and solve } \\
\text { any learning problems }\end{array}$ & $\begin{array}{c}18 / \\
78.3 \%\end{array}$ & $\begin{array}{c}5 / \\
21.7 \% \\
\end{array}$ & 0 \\
\hline $\begin{array}{l}8 \text { - I acquired a great deal of information } \\
\text { about the subject and I improved my } \\
\text { attitude }\end{array}$ & $\begin{array}{c}15 / \\
65.2 \%\end{array}$ & $\begin{array}{c}8 / \\
34.7 \%\end{array}$ & 0 \\
\hline
\end{tabular}

Many students were motivated to learn and they tried to accomplish all activities, clarify their doubts and solve any problems that occurred. The great majority assumes that they acquired a great deal of information, understanding and skills about the subject, and that it was very helpful. Some students asked their colleagues to help them solve some issues, promoting a peer-to-peer learning [9]. Some students feel that the strategies of cooperation weren't always very effective.

Critical thinking competencies are also reflected in the integrated assessment requirements incorporated into the simulation design. As Table II shows almost two thirds (or more) of the students $(69.5 \%)$ approved the use of the simulation in their project in terms of increasing their motivation to learn. A majority of $78.3 \%$ tried to clarify their doubts and learning problems and $65.2 \%$ found it helpful in organizing large amounts of information. Finally, $60.8 \%$ felt it also promotes interaction with peers. The simulation project allowed an increase in communication and enhanced a sense of community among the peers. 


\section{PROJECT OBJECTIVES}

The three broad lighting design objectives are visual performance, visual comfort and pleasantness. Energy and cost effectiveness cited for interior lighting apply also to outdoor lighting [10]. However, whereas with interior lighting it is possible to translate these objectives into a number of lighting parameters, or criteria that can be applied in all sorts of indoor situations, this was not so easily done with exterior lighting. In fact, each area of application, from road lighting to the façade of a building or monuments, parks and gardens, has its own more or less unique set of lighting criteria [11].

The design of a good floodlighting installation calls for a close study of its lighting effects. This is often the best way to decide which features will be the most attractive when floodlighted is applied [12]. Thus, the technique of floodlighting a structure is not based solely on the principles of lighting engineering, the feelings and insights as regards the aesthetic values of the architecture are just as important. It should be necessary to make sure that the floodlighting gives sufficient light for the public to find their way, or that special lighting will be required for the footpaths. It is also necessary to know if the installation will only operate for a short period, or whether it can be regarded as permanent or semi-permanent. In this case it is worthwhile considering the use of energy effective lamps, and making a more vandal-resistant installation.

When considering the lighting of a park or a garden, its function at night has to be taken in consideration and, above all, offer security. The illumination must be subtle, accentuate the beauty of the scene, since some plants should be perceived as silhouettes while others can be directly focused. The light in excess reduces the depth and destroys the mystery that exists in the place. A great garden must be illuminated near the constructions and in the limit areas. In a small garden the illumination should be restricted, choosing only a particular detail, such as a sculpture, a water feature or a special plant. If there is water in the garden, the light should be focused to emphasize each drop, tremor or movement. Some types of illumination effect used in gardens are [13]:

- Focal illumination: it is directed, attracts the attention to a specific point of the garden: shrubs, sculptures and aspects of interest;

- Indirect illumination: it slightly demarcates the garden without a focus of prominence; normally placed in the back of the plants or turned to walls or to the floor;

- General illumination: it illuminates the place widely, without detaching any specific point, perceives the garden as a whole. There are specific lights and light bulbs available for each specific situation.

The illumination of façades or monuments is essentially an artistic activity, demanding for such a detailed study of the places to illuminate [14]. One of the tasks when designing the illumination is to decide which characteristics of the building are more attractive and thus develop one project trying to enhance these same characteristics. The correct technique to illuminate a façade is not only achieved in principles established by lighting engineering, but also by understanding the aesthetic values of the architecture of the place is necessary [15].
In determining the luminance needed to give a structure the required degree of visual impact, a number of important factors have to be taken into account. The brightness of the surroundings and background has already been mentioned. Next in importance comes the nature of the building materials. There are three other aspects to be considered [16]. The first is the darkness of the materials where a higher luminance will be needed to give it a satisfactory impression of brightness. The second is for a normal installation, in which the light is directed upwards at a vertical surface, the amount of reflected light reaching an observer, and hence the brightness of the illuminated surface will decrease with the increase in the smoothness of the surface. Finally, the luminance needed will be influenced, to some extent, by the degree of matching between the spectrum of the light source employed and the color of the building material. Favorable solutions are obtained when the color of the light is near to that of the surface being illuminated [11].

In this paper are presented only two case studies of the set of projects developed. In the first one, it was performed the lighting of a city park. The second project regarded the lighting of an old square of the city.

\section{A. Case I-Dr. Manuel Braga Park}

On the right bank of the Mondego river, overlooking the river, lies one of the most pleasant urban parks of the city, much to the style of the end of the 19th century, where the flowers and garden care is enhanced, as it can be seen in Fig. 1 and 2. This park was projected in 1920 by the landscape designer Jacinto de Matos. This park is distinctive by its geometric seedbeds, with multicolour flowers that form blazons and emblems of the city.

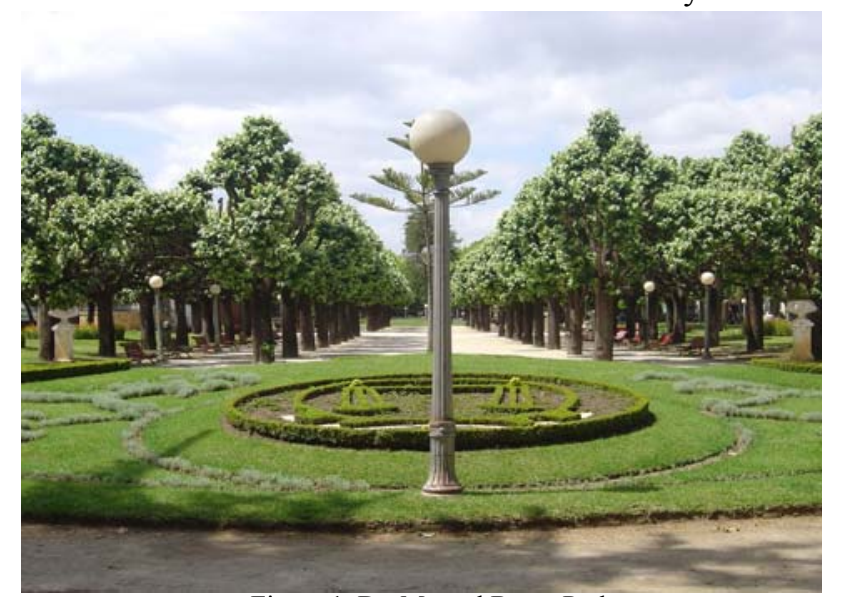

Figure 1. Dr. Manuel Braga Park

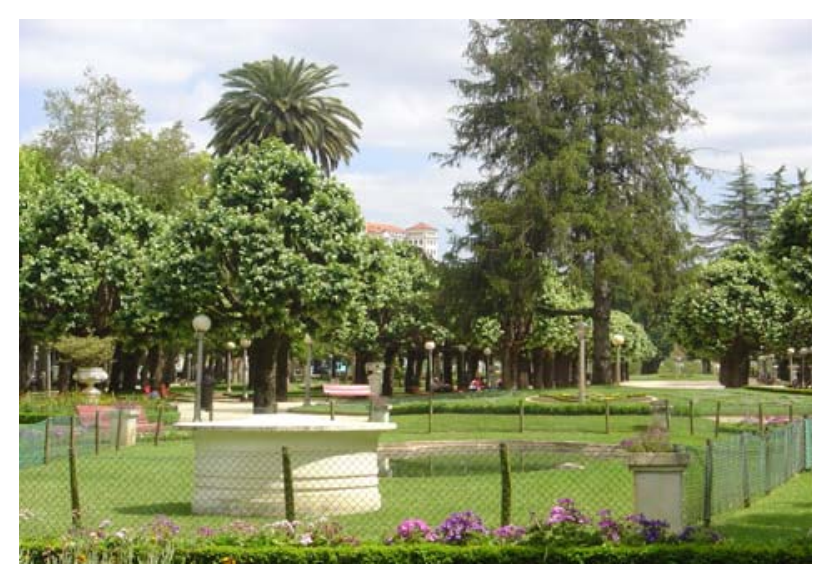


Figure 2. Pond in Dr. Manuel Braga Park

\section{B. Case II - The Old Square}

Fig. 3 presents The Old Square also known as Praça do Comércio, is the place where the charming medieval streets converge in downtown Coimbra. The Downtown area includes essentially, the Arrabalde, i.e., the Middle Ages area outside the city walls where the common people, traders and the artisans lived.

The square was the centre of the city life from where the development of the Arrabalde was started. The very topography of the area is enough to characterize it, showing how the different professions were grouped in the same streets. The names of the streets reflect the crafts of its dwellers, for example, cobblers' or shoemakers' street. Even today, the downtown area is still mainly a commercial area and this square is used monthly for a famous antiques fair. The main street, still preserves a great part of the buildings from the 18th and 19th centuries, and concentrates some of the most sophisticated stores and cafeterias. The most important monuments with historic value are the Church of S. Bartholomew (17th century, Baroque style), the Church of S. Tiago (17th century, Romanesque style), the Royal Hospital and the Pillory.

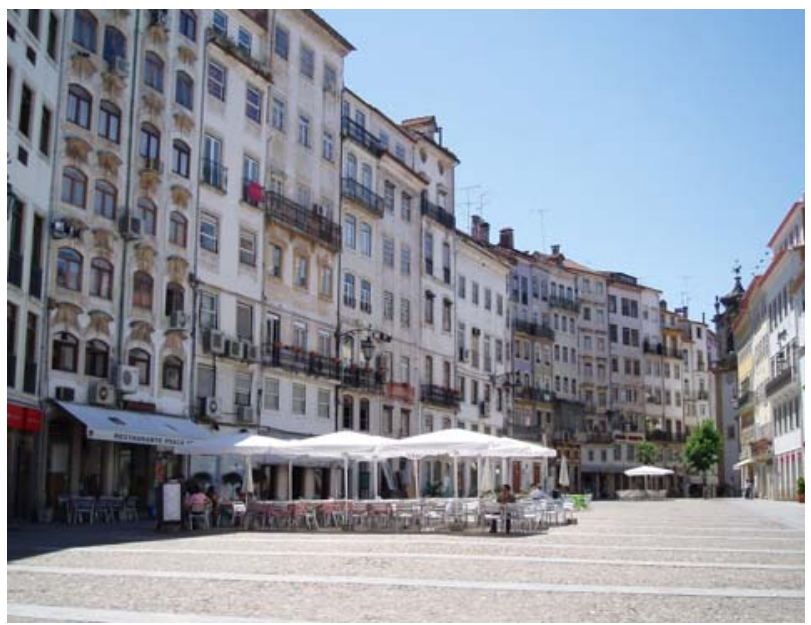

Figure 3. The Old Square

In Fig. 4 it is shown the Church of S. Tiago, positioned in one of the extremities of the square.

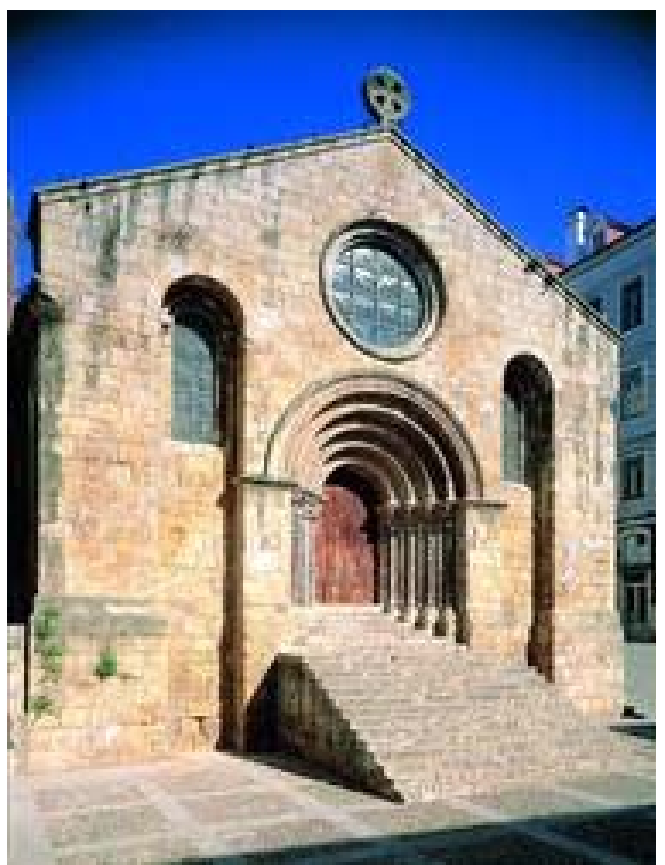

Figure 4. The Church of S. Tiago

\section{RESUlTS}

The simulation was performed using the Dialux 4.3 software package that runs in Windows Vista or XP environment. This computer program works with the international data formats of all manufacturers. The light fixture data is obtained via download from the manufacturers' websites or as an online plug-in directly from within DIALux. This program is simple and intuitive to use and the students can readily use the program without having to train themselves fully in using the software.

\section{A. Results of Case I}

In the following Fig. 5 and 6 show the images of the bandstand (coreto) in Dr. Manuel Braga park in bright daylight and at night, respectively. All the resulting images were obtained after simulation in Dialux 4.3.

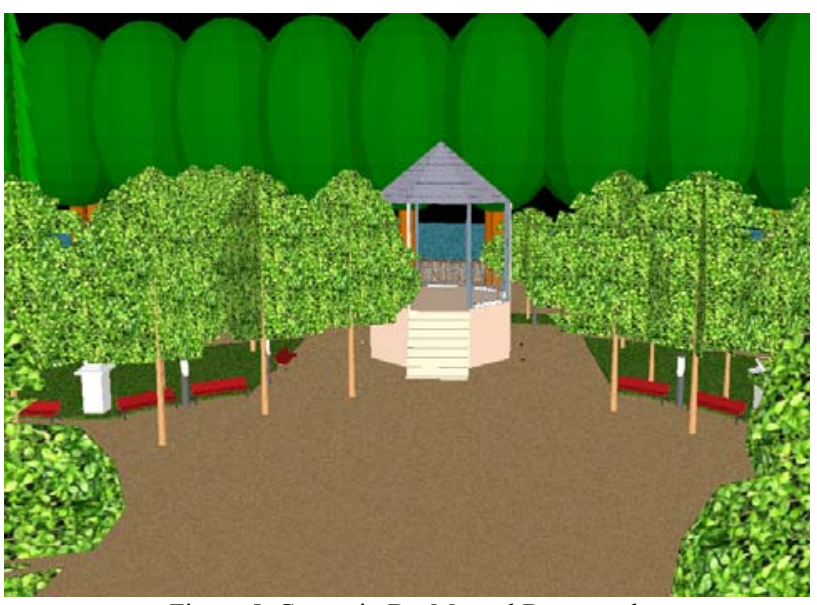

Figure 5. Coreto in Dr. Manuel Braga park 


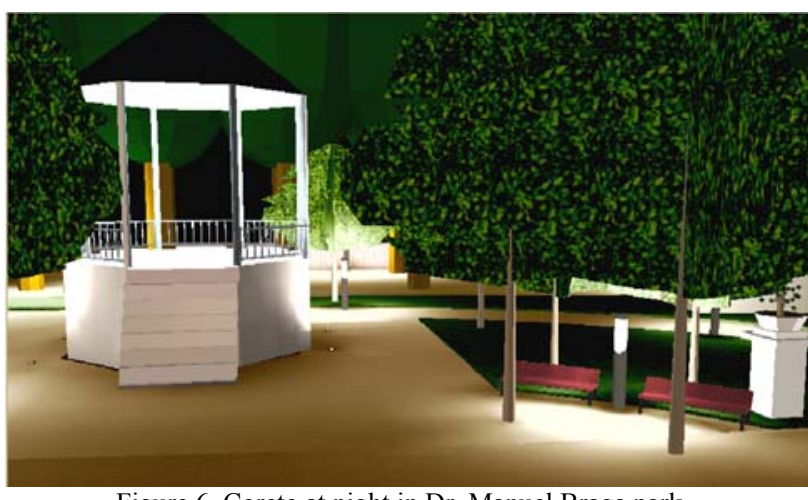

Figure 6. Coreto at night in Dr. Manuel Braga park

Fig. 7 and 8 represent images of the pond in Dr. Manuel Braga park during the day and at night, respectively.

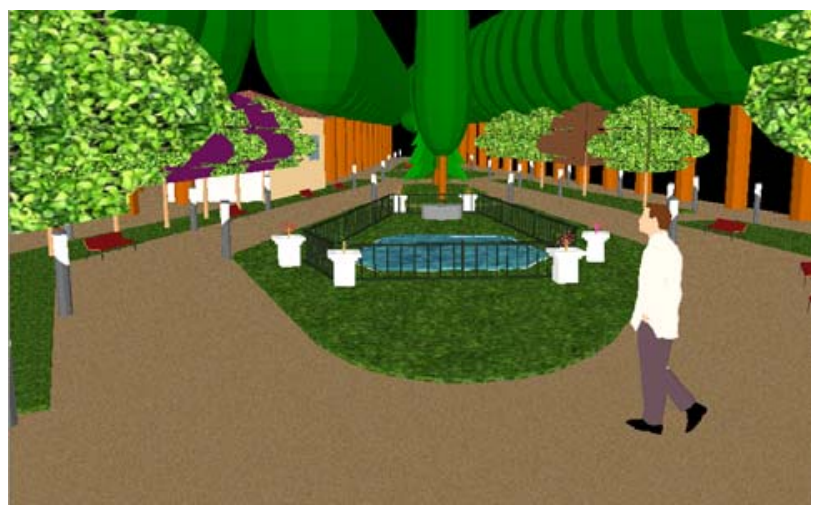

Figure 7. The Pond in Dr. Manuel Braga park

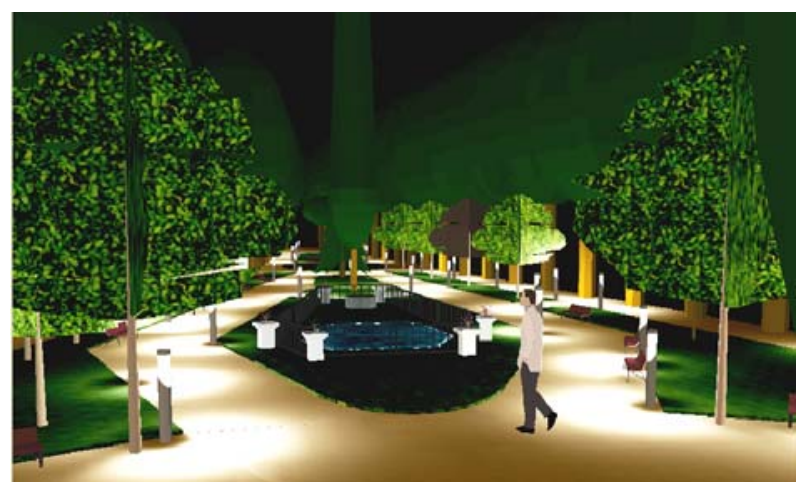

Figure 8. The pond at night in Dr. Manuel Braga park

Fig. 9 and 10 present images of Dr. Manuel Braga park in daytime and at night, respectively.

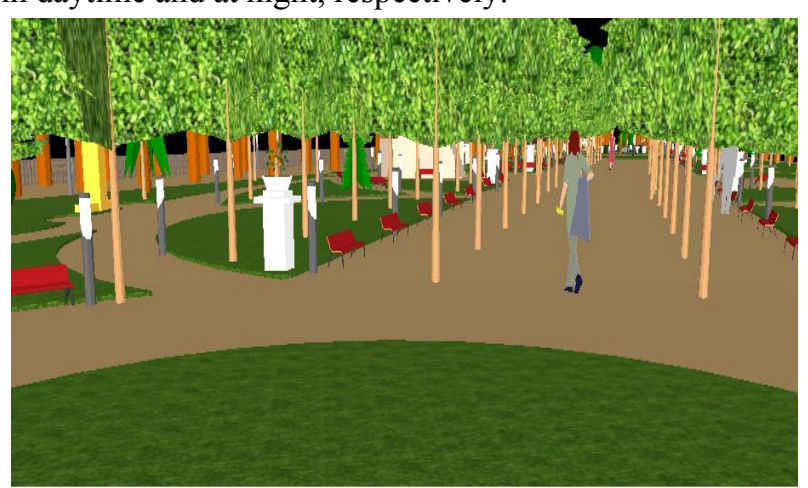

Figure 9. Dr. Manuel Braga park daylight view

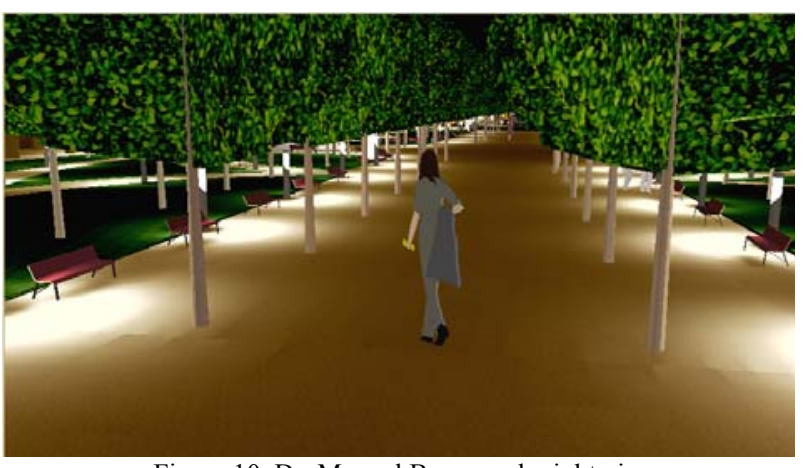

Figure 10. Dr. Manuel Braga park night view

The students measured the luminance in various points of the Dr. Manuel Braga park in order to compare with the simulation values. In Fig. 11 it is presented the lighting levels measured, before and after the study.

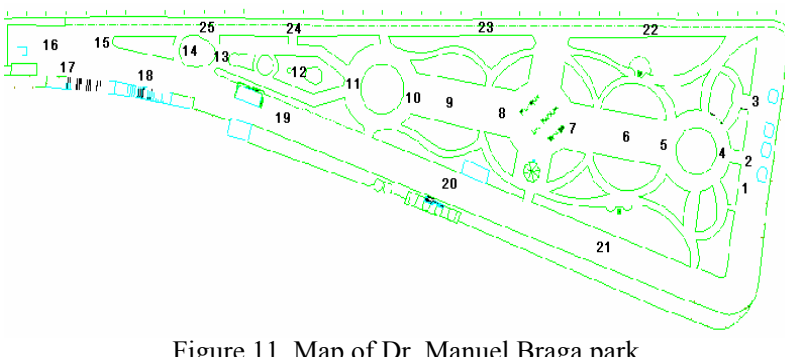

The list of the lighting levels is specified in Table III. The first column refers to the measuring points. The second and third columns show, respectively, the actual values of luminance measured and the proposed luminance levels evaluated with the DIALux software package.

TABLE III.

MEASURING POINTS AND RESPECTIVE LUMINANCE

\begin{tabular}{|c|c|c|}
\hline $\begin{array}{c}\text { Measuring } \\
\text { Points }\end{array}$ & $\begin{array}{c}\text { Obtained Values [Lux] } \\
\text { Before }\end{array}$ & $\begin{array}{c}\text { Obtained Values [Lux] } \\
\text { After }\end{array}$ \\
\hline 1 & 27.0 & 40 \\
\hline 2 & 0.9 & 40 \\
\hline 3 & 40.0 & 40 \\
\hline 4 & 3.5 & 30 \\
\hline 5 & 5.0 & 20 \\
\hline 6 & 9.0 & 10 \\
\hline 7 & 9.0 & 15 \\
\hline 8 & 9.0 & 15 \\
\hline 9 & 9.0 & 10 \\
\hline 10 & 0.8 & 20 \\
\hline 11 & 0.5 & 20 \\
\hline 12 & 0.5 & 10 \\
\hline 13 & 3.0 & 40 \\
\hline 14 & 1.5 & 15 \\
\hline 15 & 11.0 & 20 \\
\hline 16 & 0.4 & 10 \\
\hline 17 & 0.5 & 20 \\
\hline 18 & 0.7 & 20 \\
\hline 19 & 0.3 & 10 \\
\hline 20 & 0.3 & 10 \\
\hline 21 & 0.3 & 10 \\
\hline 22 & 31.0 & 20 \\
\hline 23 & 31.0 & 20 \\
\hline 24 & 31.0 & 20 \\
\hline 25 & 8.1 & 10 \\
\hline $\mathrm{E}_{\mathrm{med} .}$ [Lux] & 9.3 & 19.8 \\
\hline & & \\
\hline
\end{tabular}




\section{B. Results of Case II}

Images of The Church of S.Tiago in the Old Square in plain daylight and at night are shown respectively in Fig. 12 and 13.

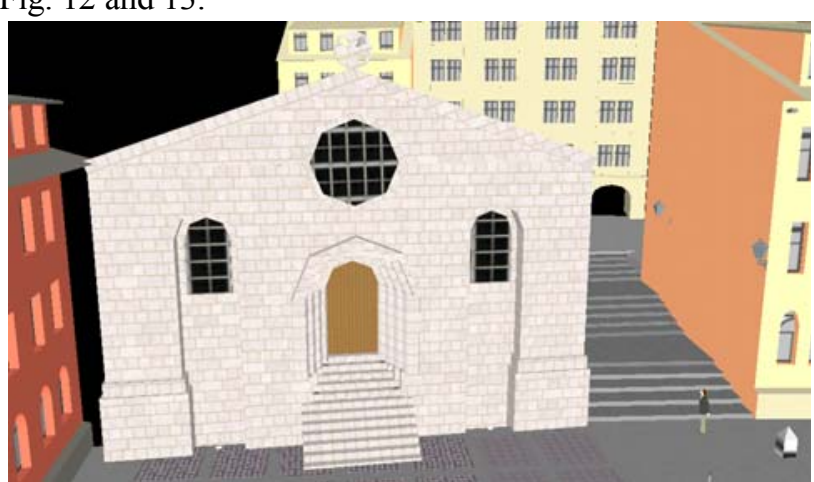

Figure 12. Church of S.Tiago at daylight in The Old Square

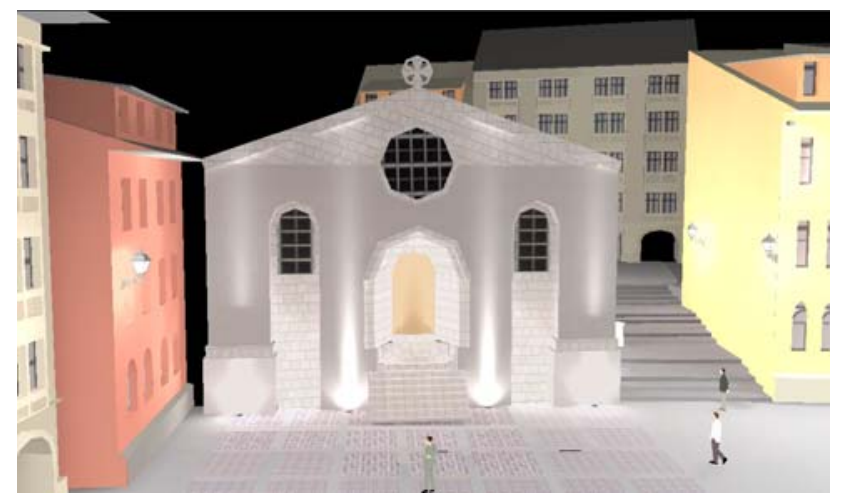

Figure 13. Church of S.Tiago at night in The Old Square

Fig. 14 and 15 show images of The Old Square during the day and at night, respectively.

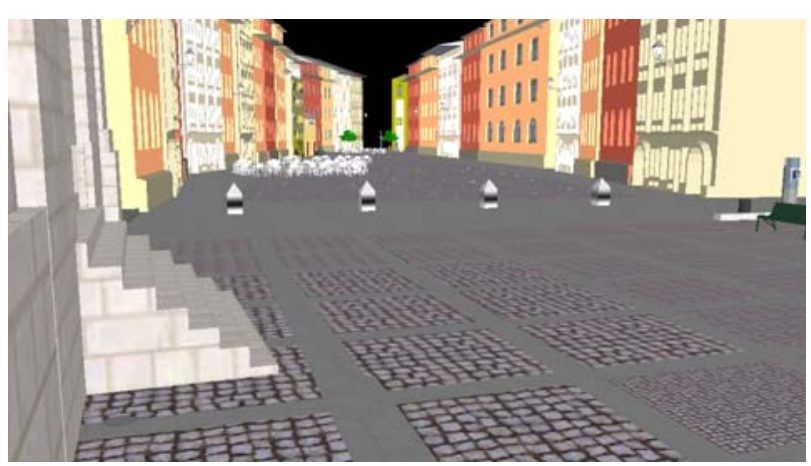

Figure 14. Daylight view of The Old Square

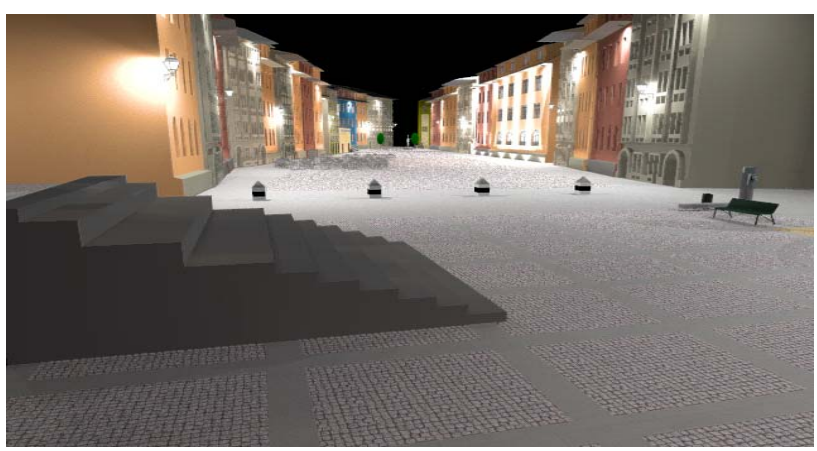

Figure 15. Night view of The Old Square

In Fig. 16 it is shown the lighting levels measured, before and after the study. Table IV gives a list of the lighting levels measured in various points before and after the simulation of The Old Square.

Figure 16. Map of The Old Square

TABLE IV.

MEASURING PoINTS AND ResPeCtive LuMinANCE

\begin{tabular}{|c|c|c|}
\hline $\begin{array}{l}\text { Measuring } \\
\text { Points }\end{array}$ & $\begin{array}{c}\text { Obtained Values [Lux] } \\
\text { Before }\end{array}$ & $\begin{array}{c}\text { Obtained Values [Lux] } \\
\text { After }\end{array}$ \\
\hline 1 & 3.0 & 80 \\
\hline 2 & 7.0 & 40 \\
\hline 3 & 4.3 & 80 \\
\hline 4 & 5.5 & 60 \\
\hline 5 & 11.5 & 60 \\
\hline 6 & 8.9 & 30 \\
\hline 7 & 25.5 & 30 \\
\hline 8 & 41.0 & 50 \\
\hline 9 & 23.0 & 60 \\
\hline 10 & 11.3 & 30 \\
\hline 11 & 51.0 & 40 \\
\hline 12 & 14.0 & 70 \\
\hline 13 & 33.0 & 60 \\
\hline 14 & 48.3 & 60 \\
\hline 15 & 49.0 & 40 \\
\hline 16 & 50.0 & 40 \\
\hline 17 & 49.0 & 40 \\
\hline 18 & 49.0 & 70 \\
\hline 19 & 50.0 & 70 \\
\hline 20 & 50.0 & 50 \\
\hline 21 & 33.0 & 60 \\
\hline 22 & 23.3 & 70 \\
\hline 23 & 12.7 & 60 \\
\hline 24 & 15.3 & 40 \\
\hline 25 & 7.3 & 40 \\
\hline 26 & 11.8 & 60 \\
\hline $\mathrm{E}_{\text {med. }}$ [Lux] & 26.5 & 53.5 \\
\hline
\end{tabular}




\section{CONCLUSIONS}

In this paper it is presented a practical approach to lighting design course in an Electrical Engineering programme. The students were expected to design a computer aided lighting project using the problem based learning model. It is possible to analyze the advantage of using correct floodlighting and to understand how software tools, like Dialux 4.3 computer program, can be useful in the study of lighting engineering projects.

The simulation design to enhance the authenticity and application of learning derived from the lighting project was used to promote skills and understanding of working collaboratively. In this project, it was paramount that both students and teachers shared responsibility for keeping up-to-date with the products of learning emanating from the simulation project. Apart from the simulation, most face-to-face contact between students occurred spontaneously or by arrangement, at their own convenience.

Technology offers plenty of new opportunities or multiple channels for expression and engagement in information processed by both academic staff and students. Simulations have the capacity to motivate learners by providing authentic learning environments and have the capacity to allow them to reproduce real world operations within the context of an organization and, above all, are devised to meet the learning objectives.

\section{ACKNOWLEDGMENT}

This study was performed in an academic project by six students: Bruno Tavares, Carmen Cabrita, Flavio Lopes, Patricia Santos, Vera Lopes and Victor Varandas. The authors also wish to thank Dr. Maria Antónia Lucas da Silva and Eng. Sidónio Simões from the Historical Centre of Coimbra and Eng. Carlos Barradas from IPPAR for their help and advice in this project.

\section{REFERENCES}

[1] J. A. Nitzke, M. L. F. Carneiro and S. R. K. Franco, "Are Computer Supported Learning Environment Really Learning Environment?", in Proc. Eleventh International World Wide Web Conference, Honolulu, Hawaii, USA 7-11 May 2002, CD-ROM.

[2] C. Milligan, "Delivering Staff and Professional Development Using Virtual Learning Environments", in JTAP Report 573, Heriot-Watt University, 1999.

[3] D. Bodemer, "Enhancing Simulation-Based Learning through Active External Integration of Representations", in Proc $26^{\text {th }}$ Annual Meeting of the Cognitive Science Sociaty, CogSci 2004, August 5-7, Chicago, 2004, [Online]. Available: http://www.cogsci.northwestern.edu/cogsci2004/papers/paper228.

[4] L. Scauble, L. E. Klopfer and K. Raghavan, "Students' transition from an engineering model to a science model of experimentation", Journal of Research in Science Teaching, vol. 28, no. 9, pp. 859-882, Nov. 1991.

[5] Software package DIALux 4.3 Manual, [Online]. Available: www.dialux.com.
[6] T. de Jong and W. R. van Joolingen, "Scientific Discovery Learning with Computer Simulations of Conceptual Domains", Review of Educational Research, vol. 2, no. 68, pp. 179-201, 1998.

[7] K. Veermans, T. de Jong and W. R. van Joolingen, "Promoting Self-Directed Learning in Simulation-Based Discovery Learning Environments Through Intelligent Support", Interactive Learning Environments, vol. 8, no. 3, December 2000, pp. 229-255.

[8] J. Zhang, Q. Chen1 and D. J. Reid, "Simulation-based scientific discovery learning: a research on the effects of experimental support and learners' reasoning ability",in Proc IFIP World Computer Congress, ICEUT2000 Educational Uses of Communication and Information Technologies, Beijing, pp. 344-350, 2000.

[9] E. Mazur, Peer Instruction: A User's Manual, Upper Saddle River, NJ: Prentice Hall, Series in Educational Innovation, 1997.

[10] Philips, Lighting Division, Eindhoven, "Lighting Manual", Fifth edition, pp. 329-347, Jan. 1993.

[11] P. Banwell, J. Brons, J. P. Freyssinier-Nova, P. Rizzo, M. Figueiro, "A demonstration of energy-efficient lighting in residential new construction", Lighting Research Technology, vol. 36, no. 2, pp. 147-164, 2004.

[12] R. H. Simons and R. Bean, Lighting Engineering: Applied Calculations, Oxford: Elsevier Science \& Technology, Architectural Press, 2000.

[13] E. Tetri, "Daylight linked dimming: effect on fluorescent lamp performance", Lighting Research and Technology. vol. 34, no. 1, pp. 3-10, 2002.

[14] Institution Of Lighting Engineers, Outdoor Lighting Guide, New York: Taylor \& Francis, 2005.

[15] G. Steffy, Architectural Lighting Design, 2nd Edition, New York: Wiley, 2002.

[16] I. Sato, Y. Sato and K. Ikeuchi, "Illumination Distribution from Brightness in Shadows: Adaptive Estimation of Illumination Distribution with Unknown Reflectance Properties in Shadow Regions", in Proc. Seventh IEEE International Conference on Computer Vision, vol. 2, pp. 875-882, 1999.

\section{AUTHORS}

Manuel Travassos Valdez is with the Electrical Engineering Department, Coimbra Polytechnic Institute (ISEC), Coimbra, Portugal (valdez@isec.pt)

Cristina Faustino Agreira is with INESC Porto and the Electrical Engineering Department, Coimbra Polytechnic Institute (ISEC), Coimbra, Portugal (cif@isec.pt)

Carlos Machado Ferreira is with INESC Coimbra and the Electrical Engineering Department, Coimbra Polytechnic Institute (ISEC), Coimbra, Portugal (cmacfer@ieee.org)

Fernando Pires Maciel Barbosa is with INESC Porto and DEEC, Faculty of Engineering of the University of Oporto, (FEUP), Porto, Portugal (fmb@fe.up.pt)

Manuscript received 09 May 2008. This work was supported in part by the U.S. Department of Commerce under Grant BS123456 (sponsor and financial support acknowledgment goes here).

Published as submitted by the author(s). 